\title{
Investigation of the Relationship between Parental Mental Disorders and Autism among the Children of West Azerbaijan -Iran
}

\author{
Arezou Kiani Equal ${ }^{1}$, Javad Rasouli ${ }^{2}$ \& Sahar Kiani ${ }^{1}$ \\ ${ }^{1}$ Department of Psychiatry, School of Medicine, Urmia University of Medical Sciences, Urmia, West Azerbaijan, \\ Iran \\ ${ }^{2}$ Department of Epidemiology and Biostatistic, School of Medicine, Urmia University of Medical Sciences, Urmia, \\ Iran \\ Correspondence: Arezou Kiani Equal, Department of Psychiatry, School of Medicine, Urmia University of \\ Medical Sciences, Urmia, West Azerbaijan, Iran. E-mail: arezoukiani@yahoo.com
}

Received: December 18, 2019

Accepted: January 21, 2020

Online Published: March 30, 2020

doi:10.5539/jmbr.v10n1p59

URL: https://doi.org/10.5539/jmbr.v10n1p59

\begin{abstract}
Background: Autism disorders have increased over the last years. Autism is a neurological growth disorder associated with social communication disorders, growth retardation, and repetitive behaviors, along with serious consequences for children and families. The purpose of this research was to evaluate the relationship between parental mental disorders and autism among the children of West Azerbaijan Province.

Methods: This research was a case-control study in which the case group subjects were selected among the parents with autistic children and control group subjects were selected among the relative parents with healthy children and non-relative parents with healthy children. Both case and control groups were matched in terms of gender, living place, and age of children. Finally, the data were analyzed using SPSS-16 (Chicago, IL, USA) software.

Results: The current research results revealed that the frequency of mental diseases, including obsessivecompulsive, inter personality sensitivity, depression, anxiety, hostility, phobia, paranoid ideation, and psychotic disorder are different in fathers and mothers of the case and control groups. As Pvalue was lower than 0.05 in all scales, there was a significant relationship between the mental diseases of parents and the history of mental disorders in relatives and autism.

Conclusion: The prevalence of mental disorders in relatives and having a medical history can be a warning sign of autism in children.
\end{abstract}

Keywords: Autism, Parental Psychiatric Disorders, Case-Control, Scl-90-R, Mental Disorder

\section{Introduction}

Autism disorders have increased over the last years. Autism spectrum disorders with delayed or abnormal functioning occur at least in one of the areas of social interaction, the language used in social imaginative or symbolic communication (Yazdani et al., 2017). Autism is a neurological growth disorder associated with social communication disorders, growth retardation, and repetitive behaviors, along with serious consequences for children and the families (Ha et al., 2015; Lei et al., 2018). It has been investigated in various studies (MAKHADIYEVA, 2018). Based on the findings of the studies conducted over the last years, the root of more than $90 \%$ of brain function abnormalities and autistic behaviors is genetic. However, genetic is not the only factor involved in the development of all cases of autism, environmental factors are also involved in the development of autistic behaviors (Karimi et al., 2017; Yuen et al., 2019). Various studies have indicated that genetic factors play a major role in autism disorders, but the impact of these symptoms has not been well understood concerning environmental risk factors. Recent research suggests that environmental factors have had an effective role in about 40 to $50 \%$ of patients with autism (Deng et al., 2015; Gaugler et al., 2014; Kim \& Leventhal, 2015; Yuen et al., 2019). Some experts reported that a wide range of parental mental disorders is associated with an autism spectrum disorder (ASD) (Bölte et al., 2007; Daniels et al., 2008; Jokiranta et al., 2013; Larsson et al., 2005). The results of the study conducted by Jokiranta et al. showed a significant relationship between parental emotional disorders and the incidence of autism in their children so that the possibility of having ASD children in the fathers with the emotional disorder is two times more than that of other fathers (Jokiranta et al., 2013). Based on the results of the study conducted by Sullivan et al., families whose first-degree relatives suffer from schizophrenia and bipolar 
disorder are at a greater risk of autism for their children (Sullivan et al., 2012). The brain growing and developing in the uterus is sensitive to environmental factors from the beginning and evaluating the non-genetic factors affecting autism is critical for identifying potential risk factors and can help to reduce the risk of this disease (Modabbernia et al., 2017). It is estimated that approximately 1.7\% of the world's population has autism, which almost $25 \%$ to $30 \%$ of children with this disease suffer from verbal problems and cannot speak. As the ability to communicate effectively is a vital skill, the inability to communicate effectively will cause many problems such as poor academic achievement, behavioral problems, and poor quality of life (Brignell et al., 2018). Due to the lack of an analytical study to evaluate the mental disorders of parents and relatives in the incidence of autism in children and as the studies conducted in this regard have been often cross-sectional and descriptive, this casecontrol research was carried out to evaluate the effects of parental mental disorders on autism, and accordingly, a major step was taken towards controlling and reducing the rate of these diseases, imposing high costs to the health system of the country.

\section{Materials \& Methods}

This case-control study received its permission (No. IR.umsu.rec.1395.333-95/8/5) from the Ethics Committee of Urmia Medical Sciences University. It also secured letters of consent from the study parents. This research is a case-control study in which the case group subjects were selected among the parents with autism children (76 mothers and 76 fathers) and control group subjects were selected among the relative parents with healthy children (149 fathers and 149 mothers) and non-relative parents with healthy children (77 fathers and 77 mothers) and the groups were compared in terms of the study variables. The research population used in this research included all children who were diagnostic to be autistic in health care centers of West Azerbaijan province. In this research, 76 autistic children (with a $1 \%$ prevalence in the community) admitted to the centers providing pediatric services for autism children in Urmia city were selected and reevaluated by the psychiatrist. After meeting the research inclusion criteria, they were included in the research. Three children were considered in the control group per one child in the case group and for each child in the case group, two healthy children of first-degree relatives and one healthy child of non relatives were considered. Subjects were matched to control the potential confounding factors. Accordingly, both groups were matched in terms of gender, living place and age, and a total of 226 participants (149 relatives and 77 non-relatives) were selected for the control group. The method of selecting the case group was as follows: by referring to the centers providing service for autistic children in Urmia, those who were diagnosed with autism were included in the research. Selection of the samples was in this way: a list of all cases was obtained in each center. Then, they were selected based on weight ratio from each center using convenient sampling method. All of the selected children whose parents were willing to participate in the research were selected as the case group. The control group for this study included 3 children versus per child in the case group. The control group also included 2 children of the relatives` selected groups due to neutralizing the confounding factors which might be created due to different ethnicities and lifestyle and cultural factors, and so on and one child was selected from non-relatives to examine the possible family and genetic factors. The relative control group included first-degree families, including uncle and aunt and non-relative control group subjects were selected from the same living place. The samples were examined by the pediatric psychiatric specialist to approve the autism of children. The SCI-90_R questionnaire was used for a parental psychiatric disorder. The initial form of this questionnaire was designed by Liminen and Curie in 1973 to show the psychological aspects of patients with somatic and mental diseases (Leathem \& Babbage 2000).The Scl-90-R checklist is the symptoms of mental disorders in the self-reporting questionnaire for screening and measuring the symptoms of mental disorders. This test was revised by Derogatis et al. based on clinical experiences and psychometric analyses. Its final form was prepared in 1976 and the internal validity of this test was reported by using alpha coefficient at the acceptable level (Derogatis et al., 1976). The reliability of this test was calculated by Cronbach's alpha method (94\%). The correlation coefficient was estimated at $88 \%$ using the test-retest method with the time interval of one year, so its validity is at a high level (Simonds et al., 2008). The criterion validity coefficients of the nine dimensions of this test with the Minnesota multidimensional questionnaire, except for obsessive-compulsivescales, was reported between $36 \%$ and $73 \%$, all of which were at the significant $(\mathrm{p}<0.05)$ (Christensen et al., 2018). The data were analyzed based on descriptive methods such as statistical tables, calculation of central indices and distribution and percentage for qualitative variables. Analytical statistical methods were also used. All analyses were performed using SPSS-16 (Chicago, IL, USA) and the significance level was considered $(\mathrm{p}<0.05)$. 


\section{Results}

Table 1. Comparing the mean psychopathologic dimensions among the mothers of three studied groups a: Significant different with controll (relative mothers with healthy children) group, b: Significant different with control2 (non-relative mothers with healthy children) group

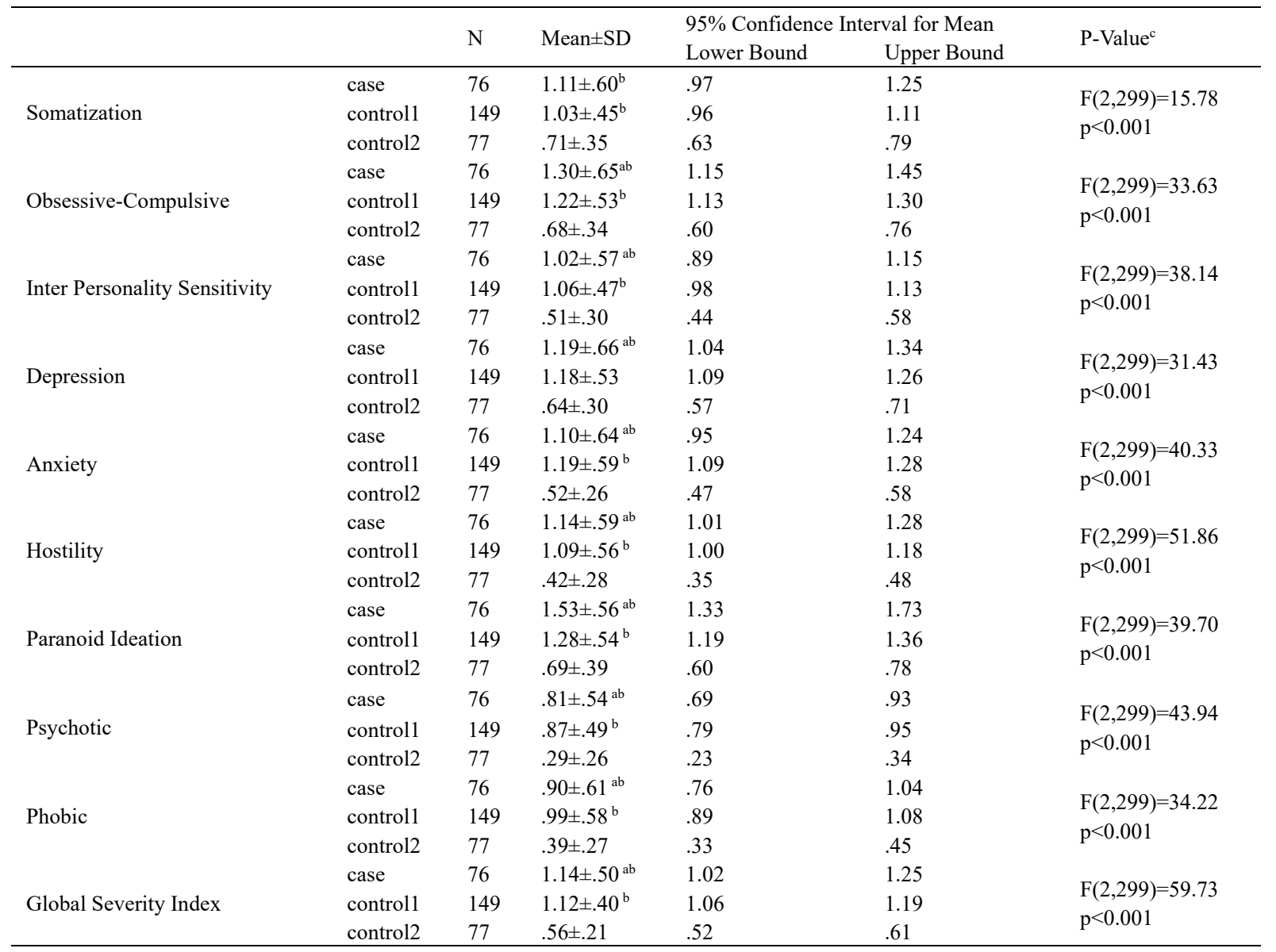

c: oneway ANOVA test

Table 2. Comparing the frequency of psychopathologic problems in the mothers of three studied groups

\begin{tabular}{|c|c|c|c|c|c|c|c|c|c|c|c|c|}
\hline & & \multicolumn{2}{|c|}{ Autism group } & \multicolumn{2}{|c|}{ Control1 $^{\mathrm{a}}$} & \multicolumn{2}{|c|}{ Control $2^{b}$} & \multirow{2}{*}{\multicolumn{2}{|c|}{$\begin{array}{l}\text { Odds ratio2 }^{c} \\
\text { (CI 95\%) }\end{array}$}} & \multirow{2}{*}{\multicolumn{2}{|c|}{$\begin{array}{l}{\text { Odds ratio } 1^{\mathrm{d}}} \\
(\text { CI } 95 \%)\end{array}$}} & \multirow{2}{*}{ P-Value ${ }^{e}$} \\
\hline & & $\mathrm{n}$ & $\%$ & $\mathrm{n}$ & $\%$ & $\mathrm{n}$ & $\%$ & & & & & \\
\hline Global Severity & Normal & 31 & 40.8 & 46 & 30.9 & 76 & 98.7 & 110.32 & (14.56- & 0.65 & $(0.37-$ & $\chi^{2}(2,97.40)$ \\
\hline Index & Psychopathologic & 45 & 59.2 & 103 & 69.1 & 1 & 1.3 & $835.95)$ & & $1.15)$ & & $<0.001$ \\
\hline \multirow{2}{*}{ Somatization } & Normal & 36 & 47.4 & 68 & 45.6 & 62 & 80.5 & 4.59 & & 0.93 & $(0.54-$ & $\chi^{2}(2,27.32)$ \\
\hline & Psychopathologic & 40 & 52.6 & 81 & 54.4 & 15 & 19.5 & \multicolumn{2}{|c|}{$(2.23-9.45)$} & 1.62) & & $<0.001$ \\
\hline \multirow{2}{*}{$\begin{array}{l}\text { Obsessive- } \\
\text { Compulsive }\end{array}$} & Normal & 28 & 36.8 & 48 & 32.2 & 64 & 83.1 & 8.44 & $(3.96-$ & 0.82 & $(0.46-$ & $\chi^{2}(2,56.59)$ \\
\hline & Psychopathologic & 48 & 63.2 & 101 & 67.8 & 13 & 16.9 & 17.99) & & 1.45) & & $<0.001$ \\
\hline \multirow{2}{*}{$\begin{array}{l}\text { Inter Personality } \\
\text { Sensitivity }\end{array}$} & Normal & 35 & 46.1 & 63 & 42.3 & 68 & 88.3 & 8.85 & $(3.86-$ & 0.86 & $(0.49-$ & $\chi^{2}(2,46.71)$ \\
\hline & Psychopathologic & 41 & 53.9 & 86 & 57.7 & 9 & 11.7 & 20.27) & & $1.50)$ & & $<0.001$ \\
\hline \multirow{2}{*}{ Depression } & Normal & 28 & 36.8 & 47 & 31.5 & 65 & 84.4 & 9.29 & (4.29- & 0.79 & $(0.44-$ & $\chi^{2}(2,60.77)$ \\
\hline & Psychopathologic & 48 & 63.2 & 102 & 68.5 & 12 & 15.6 & 20.10) & & 1.41) & & $<0.001$ \\
\hline \multirow{2}{*}{ Anxiety } & Normal & 34 & 44.7 & 47 & 31.5 & 73 & 94.8 & 22.54 & (7.48- & 0.57 & $(0.32-$ & $\chi^{2}(2,82.89)$ \\
\hline & Psychopathologic & 42 & 55.3 & 102 & 68.5 & 4 & 5.2 & $67.96)$ & & 1.01) & & $<0.001$ \\
\hline \multirow{2}{*}{ Hostility } & Normal & 28 & 36.8 & 57 & 38.3 & 74 & 96.1 & 42.29 & (12.18- & 1.06 & $(0.60-$ & $\chi^{2}(2,78.32)$ \\
\hline & Psychopathologic & 48 & 63.2 & 92 & 61.7 & 3 & 3.9 & 146.83) & & 1.88) & & $<0.001$ \\
\hline \multirow{2}{*}{ Paranoid Ideation } & Normal & 11 & 14.5 & 37 & 24.8 & 59 & 76.6 & 19.37 & (8.46- & 1.95 & $(0.93-$ & $\chi^{2}(2,79.02)$ \\
\hline & Psychopathologic & 65 & 85.5 & 112 & 75.2 & 18 & 23.4 & 44.36) & & 4.09) & & $<0.001$ \\
\hline \multirow{2}{*}{ Psychotic } & Normal & 50 & 65.8 & 80 & 53.7 & 75 & 97.4 & 19.5 & $(4.43-$ & 0.6 & $(0.34-$ & $\chi^{2}(2,44.69)$ \\
\hline & Psychopathologic & 26 & 34.2 & 69 & 46.3 & 2 & 2.6 & $85.84)$ & & 1.07) & & $<0.001$ \\
\hline \multirow{2}{*}{ Phobic } & Normal & 42 & 55.3 & 64 & 43 & 74 & 96.1 & 19.97 & $(5.78-$ & 0.61 & $(0.35-$ & $\chi^{2}(2,60.36)$ \\
\hline & Psychopathologic & 34 & 44.7 & 85 & 57 & 3 & 3.9 & $68.98)$ & & $1.06)$ & & $<0.001$ \\
\hline
\end{tabular}


In the present study, the mental disorders of the parents of autistic children were investigated as the case group (76 mothers and 76 fathers) and relative parents with healthy children (149 fathers and 149 mothers) and non-relative parents with healthy children ( 77 fathers and 77 mothers) were regarded as the control groups. Comparing the means of psychopathological dimensions showed significant difference among mothers of case and control groups in all mental dimensions (somatization, obsessive-compulsive, inter personality sensitivity, depression, anxiety, hostility, paranoid ideation, psychotic disorder, phobia) (Tables 1\&2). Comparing the mean psychopathologic dimensions of the fathers studied in three groups showed a significant difference between the fathers of the case and control groups in all psychological dimensions (somatization, obsessive-compulsive, inter personality sensitivity, depression, anxiety, hostility, paranoid ideation, psychotic disorder, and phobia) (Tables $3 \& 4$ ). As shown in Table 4, comparing the frequency of psychopathologic problems among the fathers studied in the three groups showed a significant difference between the fathers of case and control groups in all mental dimensions, so that the odds of autism in the case group was more than that in the relative control group. However, in the nonrelative control group, except for somatization, obsessive-compulsive, inter personality sensitivity and rest of the dimensions showed higher odds of autism. 180.

\section{Discussion}

The prevalence of ASD has increased remarkably over the last two decades. The Autism Diseases Control Center announced that the incidence of ASD in 2000 was 1 per 150 children (Christensen et al., 2019), while National Health Center reported it I child per 36 children in 2006, which is considered high rate (Zablotsky et al., 2017). In this research, the mental disorders were examined in parents of children with autism (case group), relative parents with healthy children, and non relative parents with healthy children (control groups). The results of this research showed that there was a significant relationship between mental disorders in the parents of children with autism (case group) and those of control group so that the odds of autism in the case group is higher than that in the relative control group. In a research conducted by Larson et al. (2005) and Jokiranta et al. (2013), in line with this study, parents' mental problems were associated with the incidence of autism in children. In a research carried out by Boukhris et al, it was reported that depression during pregnancy and the use of antidepressants during the second and third trimester of pregnancy increased the risk of ASD in children (Boukhris et al., 2016). In another study conducted by Khaiman et al, it was reported that mental disorders of parents, family history of psychiatric disorders, and high age of the father were among the most important environmental risk factors for ASD (Khaiman et al., 2015). Based on the results of this research, the odds of autism in children of fathers of case group was higher than that of non-relative and relative control groups with the dimension of obsessive compulsive disorder. Consistent with this research, Bolt et al. (2007) showed that obsessive compulsive disorder and schizophrenia are associated with autism (Bölte et al., 2007). Also, there PeerJ reviewing PDF | (2019:07:39830:0:1:NEW 10 Aug 2019) Manuscript to be reviewed is much other evidence suggesting that autism spectrum disorders, schizophrenia, bipolar disorder, and obsessive-compulsive disorder have a common molecular cause (O'Connell et al., 2018). The results of this research at the dimension of depression disorder revealed high odds of autism in relative mothers and relative and non-relative fathers in case group compared to that of the control group, but the odds of autism was low in non-relative mothers. In a study conducted by $\mathrm{Hu}$ et al, it was reported that the parents of children with ASD, experience more depressive disorder (Hu et al., 2018), compared to the parents of normal children. The results of this research also showed that the parents of children with autism will more likely have anxiety disorders. In another research conducted by Daniels et al, the findings revealed that depressive disorders are more common in mothers, but not common in fathers (Daniels et al., 2008). The results of this research revealed that mental disorder, hostility, phobia, paranoid ideation, and psychotic disorder have a significant difference between the groups of autism and their relatives and the control group. Thus, the frequency of mental disorders in relatives and having a medical history can be the risk factors of autism in children. The highest correlation was found between schizophrenic spectrum disorders in parents and non-classified pervasive developmental disorder. The results of several studies showed that there is a significant relationship between the emotional disorders of parents and the incidence of autism in their children. In the studies conducted in Sweden and Denmark, the results showed that there is a high correlation between emotional disorders and schizophrenia and ASD, and genetic studies have also proved that there is a high genetic association between these disorders (Daniels et al., 2008; Larsson et al., 2005). Families whose first-degree relatives have schizophrenia and bipolar disorder are at greater risk of autism in their children. Based on the results, these disorders have a high genetic association (Ghaziuddin, 2005). 
Table 3. Comparing the mean psychopathologic dimensions of the fathers of three studied groups

\begin{tabular}{|c|c|c|c|c|c|c|}
\hline & & \multirow{2}{*}{$\mathrm{N}$} & \multirow{2}{*}{ Mean \pm SD } & \multicolumn{2}{|c|}{ 95\% Confidence Interval for Mean } & \multirow{2}{*}{ P-Value ${ }^{c}$} \\
\hline & & & & Lower Bound & Upper Bound & \\
\hline \multirow{3}{*}{ Somatization } & case & 76 & $1.56 \pm .88^{\mathrm{ab}}$ & 1.36 & 1.76 & \multirow{3}{*}{$\begin{array}{l}F(2,299)=37.99 \\
p<0.001\end{array}$} \\
\hline & control1 & 149 & $1.29 \pm .52^{\mathrm{b}}$ & 1.21 & 1.38 & \\
\hline & control2 & 77 & $.75 \pm .31$ & .68 & .82 & \\
\hline \multirow{3}{*}{ Obsessive-Compulsive } & case & 76 & $1.53 \pm .71^{\mathrm{ab}}$ & 1.36 & 1.69 & \multirow{3}{*}{$\begin{array}{l}F(2,299)=39.93 \\
p<0.001\end{array}$} \\
\hline & control1 & 149 & $1.31 \pm .57^{\mathrm{b}}$ & 1.22 & 1.41 & \\
\hline & control2 & 77 & $.76 \pm .32$ & .68 & .83 & \\
\hline \multirow{3}{*}{ Inter Personality Sensitivity } & case & 76 & $1.36 \pm .68^{\mathrm{b}}$ & 1.21 & 1.52 & \multirow{3}{*}{$\begin{array}{l}F(2,299)=38.87 \\
p<0.001\end{array}$} \\
\hline & control1 & 149 & $1.26 \pm .53^{\mathrm{b}}$ & 1.17 & 1.34 & \\
\hline & control2 & 77 & $.68 \pm .32$ & .61 & .76 & \\
\hline \multirow{3}{*}{ Depression } & case & 76 & $1.55 \pm .72^{\mathrm{ab}}$ & 1.38 & 1.71 & \multirow{3}{*}{$\begin{array}{l}\mathrm{F}(2,299)=41.22 \\
\mathrm{p}<0.001\end{array}$} \\
\hline & control1 & 149 & $1.24 \pm .56^{\mathrm{b}}$ & 1.15 & 1.33 & \\
\hline & control2 & 77 & $.74 \pm .30$ & .67 & .81 & \\
\hline \multirow{3}{*}{ Anxiety } & case & 76 & $1.48 \pm .87^{\mathrm{ab}}$ & 1.28 & 1.68 & \multirow{3}{*}{$\begin{array}{l}F(2,299)=43.52 \\
p<0.001\end{array}$} \\
\hline & control1 & 149 & $1.19 \pm .53^{\mathrm{b}}$ & 1.11 & 1.28 & \\
\hline & control2 & 77 & $.61 \pm .30$ & .54 & .68 & \\
\hline \multirow{3}{*}{ Hostility } & case & 76 & $1.14 \pm .59^{\mathrm{b}}$ & 1.01 & 1.28 & \multirow{3}{*}{$\begin{array}{l}F(2,299)=51.86 \\
p<0.001\end{array}$} \\
\hline & control1 & 149 & $1.09 \pm .56^{\mathrm{b}}$ & 1.00 & 1.18 & \\
\hline & control2 & 77 & $.42 \pm .28$ & .35 & .48 & \\
\hline \multirow{3}{*}{ Paranoid Ideation } & case & 76 & $1.55 \pm .68^{\mathrm{ab}}$ & 1.39 & 1.70 & \multirow{3}{*}{$\begin{array}{l}F(2,299)=28.85 \\
p<0.001\end{array}$} \\
\hline & control1 & 149 & $1.29 \pm .74^{\mathrm{b}}$ & 1.17 & 1.40 & \\
\hline & control2 & 77 & $.78 \pm .33$ & .70 & .85 & \\
\hline \multirow{3}{*}{ Psychotic } & case & 76 & $.81 \pm .54^{\mathrm{b}}$ & .69 & .93 & \multirow{3}{*}{$\begin{array}{l}F(2,299)=56.29 \\
p<0.001\end{array}$} \\
\hline & control1 & 149 & $.87 \pm .49^{\mathrm{b}}$ & .79 & .95 & \\
\hline & control2 & 77 & $.29 \pm .26$ & .23 & .34 & \\
\hline \multirow{3}{*}{ Phobic } & case & 76 & $.98 \pm .61^{\mathrm{b}}$ & .84 & 1.12 & \multirow{3}{*}{$\begin{array}{l}F(2,299)=20.26 \\
p<0.001\end{array}$} \\
\hline & control1 & 149 & $.90 \pm .45^{\mathrm{b}}$ & .83 & .97 & \\
\hline & control2 & 77 & $.30 \pm .18$ & .26 & .34 & \\
\hline \multirow{3}{*}{ Global Severity Index } & case & 76 & $1.39 \pm .56^{\mathrm{ab}}$ & 1.27 & 1.52 & \multirow{3}{*}{$\begin{array}{l}F(2,299)=47.81 \\
p<0.001\end{array}$} \\
\hline & control1 & 149 & $1.18 \pm .39^{\mathrm{b}}$ & 1.12 & 1.24 & \\
\hline & control2 & 77 & $.64 \pm .18$ & .60 & .68 & \\
\hline
\end{tabular}

Table 4. Comparing the frequency of psychopathologic problems of fathers in three studied groups

\begin{tabular}{|c|c|c|c|c|c|c|c|c|c|c|c|c|}
\hline \multirow[b]{3}{*}{ Global Severity } & \multirow[b]{3}{*}{ Normal } & \multicolumn{2}{|c|}{ Autism group } & \multicolumn{2}{|c|}{ Control1 $^{\mathrm{a}}$} & \multicolumn{2}{|c|}{ Control $2^{b}$} & \multirow{2}{*}{\multicolumn{2}{|c|}{$\begin{array}{l}\text { Odds ratio2 }^{c} \\
\text { (CI 95\%) }\end{array}$}} & \multirow{2}{*}{\multicolumn{2}{|c|}{$\begin{array}{l}\text { Odds ratiol } 1^{\mathrm{d}} \\
\text { (CI 95\%) }\end{array}$}} & \multirow{3}{*}{$\frac{\text { P-Value }}{\chi^{2}(2,123.76)}$} \\
\hline & & \multirow{2}{*}{$\frac{\mathrm{n}}{21}$} & \multirow{2}{*}{$\frac{\%}{27.6}$} & \multirow{2}{*}{$\frac{\mathrm{n}}{37}$} & \multirow{2}{*}{$\frac{\%}{24.8}$} & \multirow{2}{*}{$\frac{\mathrm{n}}{76}$} & \multirow{2}{*}{$\begin{array}{l}\% \\
98.7\end{array}$} & & & & & \\
\hline & & & & & & & & 199.05 & (25.99- & 0.87 & $(0.46-$ & \\
\hline Index & Psychopathologic & 55 & 72.4 & 112 & 75.2 & 1 & 1.3 & 1524.49) & & 1.62) & & $<0.001$ \\
\hline \multirow{2}{*}{ Somatization } & Normal & 24 & 31.6 & 37 & 24.8 & 57 & 74 & 6.18 & (3.06- & 0.72 & $(0.39-$ & $\chi^{2}(2,54)$ \\
\hline & Psychopathologic & 52 & 68.4 & 112 & 75.2 & 20 & 26 & 12.47) & & $1.32)$ & & $<0.001$ \\
\hline Obsessive- & Normal & 18 & 23.7 & 36 & 24.2 & 57 & 74 & 9.18 & $(4.41-$ & 1.03 & $(0.54-$ & $\chi^{2}(2,61.77)$ \\
\hline Compulsive & Psychopathologic & 58 & 76.3 & 113 & 75.8 & 20 & 26 & 19.14) & & 1.96) & & $<0.001$ \\
\hline Inter Personality & Normal & 22 & 28.9 & 40 & 26.8 & 62 & 80.5 & 10.45 & $(4.79-$ & 0.90 & $(0.49-$ & $\chi^{2}(2,66.59)$ \\
\hline \multicolumn{2}{|r|}{ Psychopathologic } & 54 & 71.1 & 109 & 73.2 & 15 & 19.5 & $21.50)$ & & 1.66) & & $<0.001$ \\
\hline \multirow{2}{*}{ Depression } & Normal & 19 & 25 & 40 & 26.8 & 63 & 81.8 & 13.5 & $(6.20-$ & 1.10 & $(0.59-$ & $\chi^{2}(2,73.72)$ \\
\hline & Psychopathologic & 57 & 75 & 109 & 73.2 & 14 & 18.2 & 29.39) & & 2.07) & & $<0.001$ \\
\hline \multirow{2}{*}{ Anxiety } & Normal & 23 & 30.3 & 47 & 31.5 & 70 & 90.9 & 23.04 & $(9.20-$ & 1.06 & $(0.58-$ & $\chi^{2}(2,82.53)$ \\
\hline & Psychopathologic & 53 & 69.7 & 102 & 68.5 & 7 & 9.1 & $57.72)$ & & $1.93)$ & & $<0.001$ \\
\hline \multirow{2}{*}{ Hostility } & Normal & 28 & 36.8 & 57 & 38.3 & 74 & 96.1 & 42.29 & $(12.18-$ & 1.06 & $(0.60-$ & $\chi^{2}(2,78.32)$ \\
\hline & Psychopathologic & 48 & 63.2 & 92 & 61.7 & 3 & 3.9 & 146.83) & & 1.88) & & $<0.001$ \\
\hline \multirow{2}{*}{ Paranoid Ideation } & Normal & 15 & 19.7 & 41 & 27.5 & 58 & 75.3 & 12.41 & $(5.77-$ & 1.54 & $(0.79-$ & $\chi^{2}(2,63.4)$ \\
\hline & Psychopathologic & 61 & 80.3 & 108 & 72.5 & 19 & 24.7 & 26.72) & & $3.02)$ & & $<0.001$ \\
\hline \multirow{2}{*}{ Psychotic } & Normal & 39 & 51.3 & 77 & 51.7 & 77 & 100 & & & 1.02 & $(0.58-$ & $\chi^{2}(2,58.37)$ \\
\hline & Psychopathologic & 37 & 48.7 & 72 & 48.3 & 0 & 0 & & & 1.76) & & $<0.001$ \\
\hline \multirow{2}{*}{ Phobic } & Normal & 34 & 44.7 & 74 & 49.7 & 71 & 92.2 & 14.62 & $(5.66-$ & 1.22 & $(0.70-$ & $\chi^{2}(2,46.95)$ \\
\hline & Psychopathologic & 42 & 55.3 & 75 & 50.3 & 6 & 7.8 & $37.72)$ & & 2.12) & & $<0.001$ \\
\hline
\end{tabular}

a: control1: relative fathers with healthy children group, b: control2:non-relative fathers with healthy children group, c: odds ratio (abnormal/normal) ASD children fathers with relative fathers with healthy children group, d: odds ratio (abnormal/normal) ASD children fathers with non-relative fathers with healthy children group, e: chisquare test between three groups 


\section{Conclusions}

As all mental disorders have a genetic history, and autism also has a high genetic history, exposure to mental risk factors can cause mutations in the genes and cause different genetic-related problems. This research suggests that autism can be a strong genetic potential, that mental factors can activate it.

\section{Acknowledgements}

The authors would like to express their deep appreciation to all autistic health care centers and primary health care centers of West Azerbaijan province staffs and parents and participants and experts who helped in conducting the study.

\section{Conflict of interests}

The authors declare that there is no conflict of interests regarding the publication of this paper.

\section{References}

Bölte, S., Knecht, S., \& Poustka, F. (2007). A Case-Control Study of Personality Style and Psychopathology in Parents of Subjects with Autism. Journal of Autism Developmental Disorders, 37, 243-250.

Boukhris, T., Sheehy, O., Mottron, L., \& Bérard, A. (2016). Antidepressant Use During Pregnancy and the Risk of Autism Spectrum Disorder in ChildrenAntidepressant Use During Pregnancy and the Risk of AutismAntidepressant Use During Pregnancy and the Risk of Autism. JAMA Pediatrics, 170, 117-124.

Brignell, A., Chenausky, K. V., Song, H., Zhu, J., Suo, C., \& Morgan, A. T. (2018). Communication interventions for autism spectrum disorder in minimally verbal children. Cochrane Database of Systematic Reviews.

Christensen, D. L., Braun, K. V. N., Baio, J., Bilder, D., Charles, J., Constantino, J. N., ..., \& Yeargin-Allsopp, M. (2018). Prevalence and Characteristics of Autism Spectrum Disorder Among Children Aged 8 Years Autism and Developmental Disabilities Monitoring Network, 11 Sites, United States, 2012. Morbidity and mortality weekly report Surveillance summaries (Washington, DC: 2002), 65, 1-23.

Christensen, D. L., Maenner, M. J., Bilder, D., Constantino, J. N., Daniels, J., Durkin, M. S., ..., \& Robinson, C. (2019). Prevalence and Characteristics of Autism Spectrum Disorder Among Children Aged 4 Years-Early Autism and Developmental Disabilities Monitoring Network, Seven Sites, United States, 2010, 2012, and 2014. J MMWR Surveillance Summaries, 68, 1.

Daniels, J. L., Forssen, U., Hultman, C. M., Cnattingius, S., Savitz, D. A., Feychting, M., \& Sparen, P. (2008). Parental Psychiatric Disorders Associated With Autism Spectrum Disorders in the Offspring. J Pediatrics.

Deng, W., Zou, X., Deng, H., Li, J., Tang, C., Wang, X., \& Guo, X. (2015). The Relationship Among Genetic Heritability, Environmental Effects, and Autism Spectrum Disorders:37 Pairs of Ascertained Twin Study. Journal of Child Neurology, 30, 1794-1799.

Derogatis, L. R., Rickels, K., \& Rock, A. F. (1976). The SCL-90 and the MMPI: A Step in the Validation of a New Self-Report Scale. British Journal of Psychiatry, 128, 280-289.

Gaugler, T., Klei, L., Sanders, S. J., Bodea, C. A., Goldberg, A. P., Lee, A. B., ..., \& Buxbaum, J. D. (2014). Most genetic risk for autism resides with common variation. Nature Genetics, 46, 881. Retrieved from https://www.nature.com/articles/ng.3039\#supplementary-information

Ghaziuddin, M. (2005). A family history study of Asperger syndrome. Journal of Autism Developmental Disorders, $35,177-182$.

Ha, S., Sohn, I.-J., Kim, N., Sim, H. J., \& Cheon, K.-A. (2015). Characteristics of Brains in Autism Spectrum Disorder: Structure, Function and Connectivity across the Lifespan. Exp Neurobiol, 280(24), 273-284.

Hu, X., Yin, L., Situ, M., Guo, K., Yang, P., Zhang, M., \& Huang, Y. (2018). Parents' impaired emotion recognition abilities are related to children's autistic symptoms in autism spectrum disorder. Neuropsychiatric disease and treatment, 14, 2973-2980.

Jokiranta, E., Brown, A. S., Heinimaa, M., Cheslack-Postava, K., Suominen, A., \& Sourander, A. (2013). Parental psychiatric disorders and autism spectrum disorders. Psychiatry Research, 207, 203-211.

Karimi, P., Kamali, E., Mousavi, S. M., \& Karahmadi, M. (2017). Environmental factors influencing the risk of autism. Journal of Research in Medical Sciences: The Official Journal of Isfahan University of Medical Sciences, 22, 27-27. 
Khaiman, C., Onnuam, K., Photchanakaew, S., Chonchaiya, W., \& Suphapeetiporn, K. (2015). Risk factors for autism spectrum disorder in the Thai population. European Journal of Pediatrics, 174,1365-1372.

Kim, Y. S., \& Leventhal, B. L. (2015). Genetic Epidemiology and Insights into Interactive Genetic and Environmental Effects in Autism Spectrum Disorders. Biological Psychiatry, 77, 66-74.

Larsson, H. J., Eaton, W. W., Madsen, K. M., Vestergaard, M., Olesen, A. V., Agerbo, E., Schendel, D., Thorsen, P., \& Mortensen, P. B. (2005). Risk Factors for Autism: Perinatal Factors, Parental Psychiatric History, and Socioeconomic Status. American Journal of Epidemiology, 161, 916-925.

Yazdani, M., Hemayat Talab, R., Homanian, D. (2017). Pharmacophore, 8(6), 77-86.

Leathem, J. M., \& Babbage, D. R. (2000). Affective disorders after traumatic brain injury: Cautions in the use of the Symptom Checklist-90-R. The Journal of Head Trauma Rehabilitation, 15, 1246-1255.

Lei, X.-Y., Li, Y.-J., Ou, J.-J., \& Li, Y.-M. (2018). Association between parental body mass index and autism spectrum disorder: A systematic review and meta-analysis. J European Child Adolescent Psychiatry, 1-15.

MAKHADIYEVA, A., KUDYSHEVA, A., Kadisha, S. H. (2018). RESULTS OF ANALYSIS OF THE FAMILY VALUES DESTRUCTION IN FAMILIES WITH A CHILD WITH AUTISM SPECTRUM DISORDER (ASD). Journal Of Organizational Behavior Research, 3(2), 137-145.

Modabbernia, A., Velthorst, E., \& Reichenberg, A. (2017). Environmental risk factors for autism: An evidencebased review of systematic reviews and meta-analyses. J Molecular Autism, 8, 13.

O'Connell, K. S., McGregor, N. W., Lochner, C., Emsley, R., \& Warnich, L. (2018). The genetic architecture of schizophrenia, bipolar disorder, obsessive-compulsive disorder and autism spectrum disorder. Molecular and Cellular Neuroscience, 88, 300-307.

Simonds, E. C., Handel, R. W., \& Archer, R. P. (2008). Incremental Validity of the Minnesota Multiphasic Personality Inventory-2 and Symptom Checklist-90-Revised With Mental Health Inpatients, 15, 78-86.

Sullivan, P. F., Magnusson, C., Reichenberg, A., Boman, M., Dalman, C., Davidson, M., \& Fruchter, E. (n. d.). Family History of Schizophrenia and Bipolar Disorder as Risk Factors for Autism Family History of Psychosis as Risk Factor for ASD. JAMA Psychiatry, 69, 1099-1103.

Yuen, R. K., Szatmari, P., \& Vorstman, J. A. (2019). Genetics of Autism Spectrum. J Autism Pervasive Developmental Disorders, 112.

Zablotsky, B., Black, L. I., \& Blumberg, S. (2017). Estimated prevalence of children with diagnosed developmental disabilities in the United States, 2014-2016. J NCHS Data Brief, 1-8.

\section{Copyrights}

Copyright for this article is retained by the author(s), with first publication rights granted to the journal.

This is an open-access article distributed under the terms and conditions of the Creative Commons Attribution license (http://creativecommons.org/licenses/by/4.0/). 